Part of Journal of Research of the National Bureau of Standards, Volume 17, December 1936

\title{
BOILING-POINT-COMPOSITION DIAGRAM FOR DILUTE AQUEOUS SOLUTIONS OF DEUTERIUM OXIDE
}

\author{
By Edgar R. Smith and Mieczysław Wojciechowski ${ }^{1}$
}

\section{ABSTRACT}

The differences between the boiling points of dilute aqueous solutions of heavy water and the boiling point of ordinary water were measured in the range from 0.3 to 7 percent of $\mathrm{D}_{2} \mathrm{O}$. The boiling points were found to increase linearly with increase in $\mathrm{D}_{2} \mathrm{O}$, according to the equation mole $\%$ of $\mathrm{D}_{2} \mathrm{O}=70.9(\Delta T)$, where $\Delta T$ is the boiling point in degrees centigrade minus 100 . The measurements, made with ebulliometers of the type devised by W. Swiętosławski, were found to offer a rapid method for the analysis of solutions of heavy water.

The differences between the boiling points and condensation temperatures of the same solutions were measured in a differential ebulliometer which gave a fractionation equivalent to about one theoretical plate. The small separation between the vapor and liquid lines on the boiling-point-composition diagram shows that the separation of heavy water by fractional distillation would require columns of extremely high efficiency.

\section{CONTENTS}

I. Introduction_._.

II. Materials and method. 842

III. Experimental results and conclusions

IV. References.

\section{INTRODUCTION}

It has been shown [6] ${ }^{2}$ that the freezing points of mixtures of $\mathrm{H}_{2} \mathrm{O}$ and $\mathrm{D}_{2} \mathrm{O}$ can be expressed by the equation $t=4.213 x-0.411 x^{2}$, where $t$ is the freezing point in degrees centigrade, and $x$ is the mole fraction of $\mathrm{D}_{2} \mathrm{O}$. The solidus-liquidus curves nearly coincide, the maximum difference between them being $0.02^{\circ}$ at about 42 percent of $\mathrm{D}_{2} \mathrm{O}$ [2], so that very little separation can be effected by fractional crystallization [3]. On the other hand, it has been shown $[4,5,7,18]$ that an appreciable separation can be obtained by fractional distillation. While the electrolytic method of concentrating $\mathrm{D}_{2} \mathrm{O}$ is economical and convenient in the last stages, a great deal of energy is required to electrolyze the large initial amount of water to a small volume. For this reason it appeared desirable to investigate the relation between the compositions of the liquid and vapor phases in equilibrium at the normal boiling points of mixtures of $\mathrm{H}_{2} \mathrm{O}$ and $\mathrm{D}_{2} \mathrm{O}$ in the dilute range, up to about 7 percent of $\mathrm{D}_{2} \mathrm{O}$.

1 Guest worker from the Polytechnic Institute, Warsaw, Poland.

2 The figures in brackets refer to references listed at the end of the paper. 


\section{MATERIALS AND METHOD}

Five mixtures of $\mathrm{H}_{2} \mathrm{O}$ and $\mathrm{D}_{2} \mathrm{O}$, containing approximately $0.3,0.7$, $1.0,3.2$, and 7.0 percent of $\mathrm{D}_{2} \mathrm{O}$, were prepared by electrolysis. These were purified by distillation from alkaline permanganate followed by simple distillation, with the rejection of equal initial and final portions. The density of each purified mixture was determined by the differential method of twin quartz pycnometers [14,19] and the mole fraction $x$ of $\mathrm{D}_{2} \mathrm{O}$ in each was calculated from the equation $x=9.416 \Delta S-1.00$ $(\Delta S)^{2}$, where $\Delta S=S-1$, and $S$ is the specific gravity of the mixture at $25^{\circ}$, compared with normal water at $25^{\circ}$. This equation was derived from that of Luten [9], $S=1.0000+0.1044 x+0.0012 x^{2}$, using the recent value of 1.1074 obtained by Tronstad, Nordhagen, and

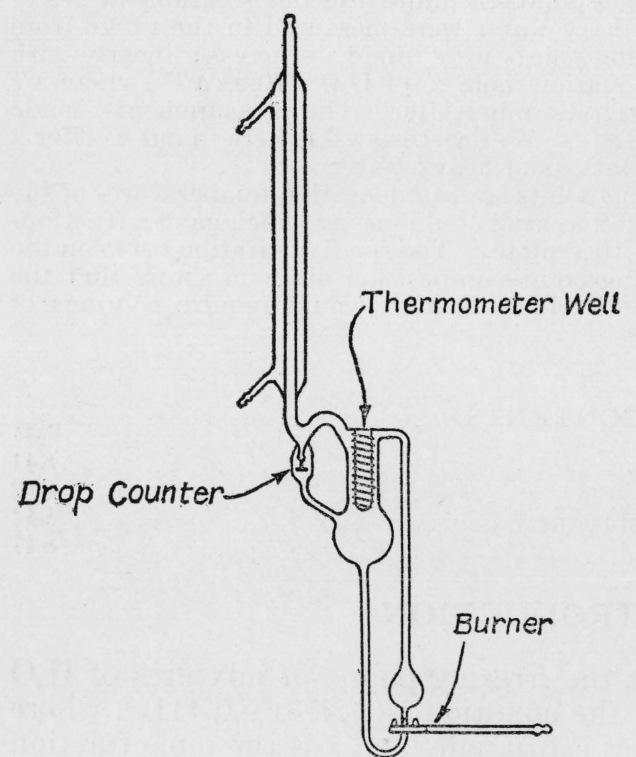

FIGURE 1.-Simple barometric ebulliometer. Brun [17], for the specific gravity of pure $\mathrm{D}_{2} \mathrm{O}$ at $25^{\circ}$.

For the determination of the boiling points of the mixtures, two identical simple barometric ebulliometers of the type developed by Swiętosławski [15], shown in figure 1 , were used. ${ }^{3}$ One of these was filled with purified normal water, the other with the mixture to be investigated, and they were mounted side by side at the same level. Both waters were boiled continuously at the same rate, as measured by means of the drop counters below the condensers in the ebulliometers. The boiling points, measured as described below, were found to remain constant within wide limits of the rate of boiling, showing that superheating did not occur, so a convenient rate within these limits was adopted.

The difference between the boiling point of each mixture and that of normal water was determined in the following way. The resistance of a calibrated platinum-resistance thermometer (coiled-filament type) [10], immersed in the mercury-filled thermometer well of the ebulliometer containing normal water, was measured with a calibrated Mueller thermometer bridge. A stop watch was started and the thermometer was quickly transferred to the ebulliometer containing the mixture. After a 5-minute interval, the resistance of the thermometer in the mixture was measured and then the thermometer was quickly transferred back to the ebulliometer containing normal water. After another 5-minute interval the resistance of the thermometer at the boiling point of normal water was again measured, and the pro-

\footnotetext{
${ }_{3}$ The ebulliometers used in this work were made by Stefan Obojski, glassblower at the Polytechnic Institute, Warsaw, Poland, to conform to the specifications of W. Świętosławski.
} 
cedure repeated to obtain a continuous series of 13 readings at equal time intervals. In this way, the average of each two successive measurements on normal water gave the value of the resistance which the thermometer would have had at the boiling point of normal water if measured at the same time and pressure as the intermediate measurement on the mixture. Ordinary variations which occur in atmospheric pressure make this procedure necessary for precise work since a change of only $0.03 \mathrm{~mm}$ in pressure changes the boiling point of water by $0.001^{\circ} \mathrm{C}$, and in this work changes of less than $0.001^{\circ} \mathrm{C}$ were measured. To illustrate the procedure, the data obtained for the mixture containing 6.955 percent of $\mathrm{D}_{2} \mathrm{O}$ are given in table 1 .

TABLE 1.-Data for mixture containing 6.995 mole $\%$ of $\mathrm{D}_{2} \mathrm{O}$

\begin{tabular}{|c|c|c|c|c|}
\hline \multirow[b]{2}{*}{ Mixture } & \multicolumn{3}{|c|}{ Resistance in international ohms } & \multirow[b]{2}{*}{$\Delta T$} \\
\hline & $\begin{array}{l}\text { Individual } \\
\text { readings }\end{array}$ & $\begin{array}{c}\text { Average } \\
\text { normal } \\
\text { water }\end{array}$ & $\begin{array}{c}\text { Average } \\
\mathrm{D}_{2} \mathrm{O} \\
\text { mixture }\end{array}$ & \\
\hline Normal water & \multirow{4}{*}{$\begin{array}{l}35.200020 \\
35.20990 \\
35.20015 \\
35.21008 \\
35.20045\end{array}$} & & & ${ }^{\circ} \mathrm{C}$ \\
\hline $\begin{array}{l}\mathrm{D}_{2} \mathrm{O} \text { mixture-- } \\
\text { Normal water. }\end{array}$ & & 35.20018 & & \multirow{3}{*}{$\begin{array}{r}0.0972 \\
.0984 \\
.0978 \\
.0979\end{array}$} \\
\hline $\mathrm{D}_{2} \mathrm{O}$ mixture & & 35.20030 & $\begin{array}{l}3.2099 \\
-0.29-1\end{array}$ & \\
\hline water.. & & & 35.21024 & \\
\hline $\begin{array}{l}\mathrm{D}_{2} \mathrm{O} \text { mixture } \\
\text { Normal water-.... }\end{array}$ & \multirow{3}{*}{$\begin{array}{l}35.21040 \\
35.20060 \\
35.21065 \\
35.20088 \\
35.21075\end{array}$} & 35. 20053 & 35.21053 & \multirow{3}{*}{$\begin{array}{l}.0997 \\
.0993 \\
.0991 \\
.0982 \\
.0991\end{array}$} \\
\hline $\begin{array}{l}\mathrm{D}_{2} \mathrm{O} \text { mixture--. } \\
\text { Normal water }\end{array}$ & & 35.20074 & 3501070 & \\
\hline $\mathrm{D}_{2} \mathrm{O}$ mixture & & 35.20084 & 30.21060 & \\
\hline $\begin{array}{l}\text { Normal water } \\
\mathrm{D}_{2} \mathrm{O} \text { mixture- }\end{array}$ & \multirow{2}{*}{$\begin{array}{l}35.20080 \\
35.21023 \\
35.20080\end{array}$} & 35.20080 & 35. 21049 & \multirow[t]{2}{*}{$\begin{array}{l}.0969 \\
.0943\end{array}$} \\
\hline Normal water & & & & \\
\hline
\end{tabular}

Average $\Delta T=0.0980 \pm 0.0011^{\circ} \mathrm{C}$

Each measurement on normal water is also bracketed between two equally spaced measurements on the $\mathrm{D}_{2} \mathrm{O}$ mixture, thus giving the series of differences in boiling points shown in column 5 of table 1 . Within the precision of the differences measured, each $0.0001 \mathrm{ohm}$ is equivalent to $0.001^{\circ}$ for the thermometer used, so that the difference between the boiling point of the $\mathrm{D}_{2} \mathrm{O}$ mixture and the boiling point of normal water under the same pressure is obtained by multiplying the difference in resistance by 10 . From the measurements of Miles and Menzies [11] on the vapor pressure of pure deuterium water, it is certain that the ratio $d T / d p$ for dilute aqueous solutions of $\mathrm{D}_{2} \mathrm{O}$ is very close to the same ratio for ordinary water at $100^{\circ}$. Consequently the difference in boiling point found at the average pressure prevailing during the measurement (within $10 \mathrm{~mm}$ of normal) is the same, within the precision of the measurements, as the difference under normal pressure. The boiling point of water containing 6.955 mole percent of $\mathrm{D}_{2} \mathrm{O}$ is therefore $100.098 \pm 0.001^{\circ} \mathrm{C}$.

The difference between the boiling point and condensation temperature of each mixture was measured in a differential ebulliometer, of the type standardized by Swiętosławski [15], shown in figure 2 . The resistance of the thermometer was measured in the lower thermometer well, a stop watch was started and the thermometer quickly transferred to the upper well. After a 5-minute interval the resis- 
tance of the thermometer in the upper well was measured and then the thermometer was transferred back to the lower well again. After another 5-minute interval the resistance at the boiling point was again measured, and the procedure was repeated to obtain a series of readings at equally spaced intervals of time. By this method differences due to changes in barometric pressure during the measurements were rendered negligible, as in the measurements of boiling point with the simple ebulliometers. The differential ebulliometer thus served as its own barometer. The precision obtained was first determined

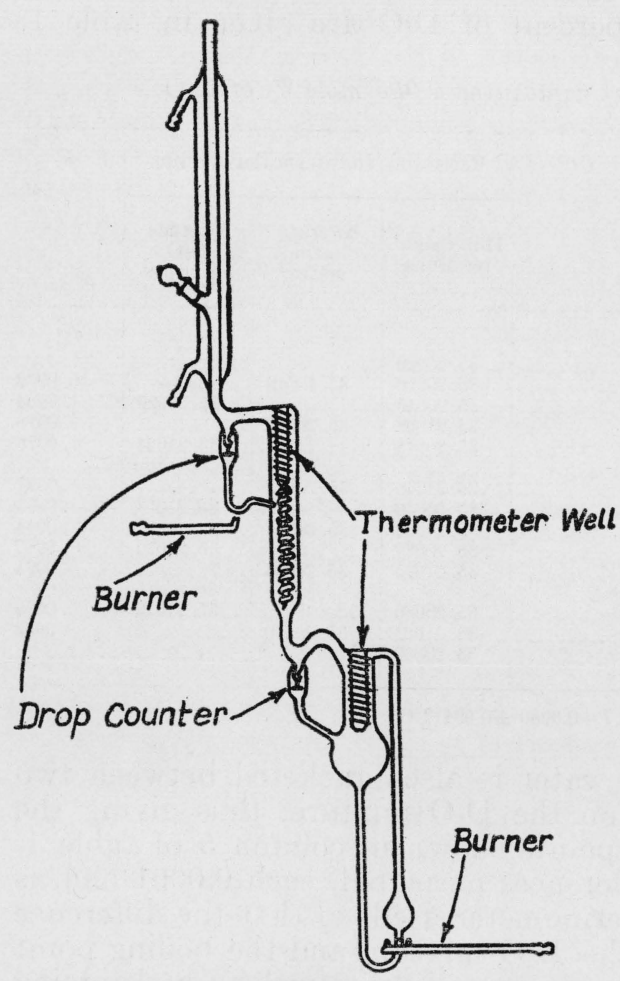

Figure 2.-Differential ebulliometer.

by using normal water in the differential ebulliometer and measuring 11 successive values of the difference between the boiling and condensation temperatures. The results showed that, within a few ten thousandths of $1^{\circ}$, there was no difference between these two temperatures in the case of ordinary water and, in addition, that equilibrium was obtained without superheating effects and that the water had been adequately purified.

\section{EXPERIMENTAL RESULTS AND CON- CLUSIONS}

In table 2 the values in the first column are the measured differences in density between the solutions and normal water, the second column shows the corresponding values of $\Delta S$, the third contains the calculated mole percent of $\mathrm{D}_{2} \mathrm{O}$ in each solution, the fourth gives the difference between the boiling point of each solution and the boiling point of normal water, as measured with the simple barometric ebulliometers, and the fifth column shows the difference between the boiling point of each solution and the temperature of condensation of its vapor in the differential ebulliometer.

To obtain the composition of the vapor in equilibrium with the boiling solution, the number of theoretical plates equivalent to the space between the thermometer wells in the differential ebulliometer, considered as a fractionating column, was determined. For this determinination two binary mixtures were used for which the boilingpoint-composition data for the liquid and vapor phases seem to be well known. These were benzene-ethylene chloride $[12,13]$ and heptane-toluene [1], the data for the latter system being apparently more 
TABLE 2.-Boiling-point-composition data for dilute solutions of $\mathrm{D}_{2} \mathrm{O}$

\begin{tabular}{|c|c|c|c|c|}
\hline$\Delta D$ & $\Delta S=\frac{10^{6} \Delta D}{0.99707}$ & $\begin{array}{c}\text { Mole } \% \text { of } \\
\mathrm{D}_{2} \mathrm{O}\end{array}$ & $\begin{array}{c}\Delta T \\
\left(\mathrm{bp}-100^{\circ}\right)\end{array}$ & $\left(\begin{array}{c}\Delta t \\
(\mathrm{bp}-C . T .)\end{array}\right.$ \\
\hline $\begin{array}{l}\text { ppm } \\
7,099 \\
7,349\end{array}$ & $\begin{array}{r}0.000330 \\
.000722 \\
.001102 \\
.003359 \\
.007392 \\
(.1074)\end{array}$ & $\begin{array}{r}0.311 \\
.680 \\
\text { 1. } 038 \\
\text { 3. } 162 \\
6.955 \\
\text { (100.) }\end{array}$ & $\begin{array}{r}0.0039 \\
.0090 \\
.0149 \\
.0444 \\
.0980 \\
(1.40)\end{array}$ & $\begin{array}{r}0.0014 \\
.0014 \\
.0013 \\
.0016 \\
.0020 \\
.0 .0\end{array}$ \\
\hline
\end{tabular}

consistent and reliable than those for the former. The method was to fill the differential ebulliometer with a mixture of known composition, measure the difference between the boiling point and condensation temperature, and from the known boiling-point-composition diagram for the system, to determine graphically the corresponding number of theoretical plates. The plate equivalent of the differential ebulliometer was found to be 0.90 with the benzene-ethylene chloride mixture and 0.96 with the heptane-toluene mixture. The value of slightly less than one theoretical plate indicates that although a temperature equilibrium, within a few hundredths of $1^{\circ}$, was attained between the boiling and condensation temperatures, the true composition equilibrium between the liquid and vapor phases was not attained, probably because of the rapid rate of boiling required to pump the mixture of liquid and vapor over the lower thermometer well (fig. 2). However, for the purpose of this investigation it is sufficiently accurate to consider the differential ebulliometer as equivalent to one theoretical plate.

The relation between normal boiling point and composition of the system $\mathrm{H}_{2} \mathrm{O}-\mathrm{D}_{2} \mathrm{O}$ is shown graphically in figure 3 . The boiling point increases linearly with increase in $\mathrm{D}_{2} \mathrm{O}$, the largest deviation of any point from the straight line labeled "liquid" being only a few tenthousand ths of $1^{\circ}$. This line is represented by the equation

$$
\text { mole } \% \text { of } \mathrm{D}_{2} \mathrm{O}=70.9 \Delta T \text {, }
$$

in which $\Delta T$ is the increase in normal boiling point accompanying the increase in $\mathrm{D}_{2} \mathrm{O}$. The ease and rapidity with which comparisons of boiling points can be made with precision, by means of the ebulliometric technique of Swiętosławski, suggests this method as a convenient analytical procedure for following the early stages in the production of heavy water. The linearity of the relation evidently extends through the entire range of composition since, by extrapolation of the straight line, or calculation from equation 1 , a value of $101.41^{\circ} \mathrm{C}$ is obtained for the boiling point of pure $\mathrm{D}_{2} \mathrm{O}$ as compared with $101.42^{\circ}$ measured by Lewis and Macdonald [8], and $101.40 \pm$ $0.016^{\circ} \mathrm{C}$ obtained by Miles and Menzies [11] from vapor-pressure measurements.

The curve labeled "vapor" in figure 3 shows the composition of the vapor in equilibrium with the boiling mixtures and is based on the value of 1 for the theoretical-plate equivalent of the differential ebulliometer. The closeness of the vapor and liquid composition lines indicates that a large number of theoretical plates would be required in a fractionating column to effect much separation. 
Although the system consists of two components, $\mathrm{H}_{2} \mathrm{O}$ and $\mathrm{D}_{2} \mathrm{O}$, there are in reality three substances present, because of the reaction

$$
\mathrm{H}_{2} \mathrm{O}+\mathrm{D}_{2} \mathrm{O}=2 \mathrm{HDO} \text {. }
$$

Topley and Eyring [16] have calculated the equilibrium constant $K$ of this reaction to be 3.26 , while the simple assumption of random distribution [7] gives 4 for the constant. In dilute solution the use of

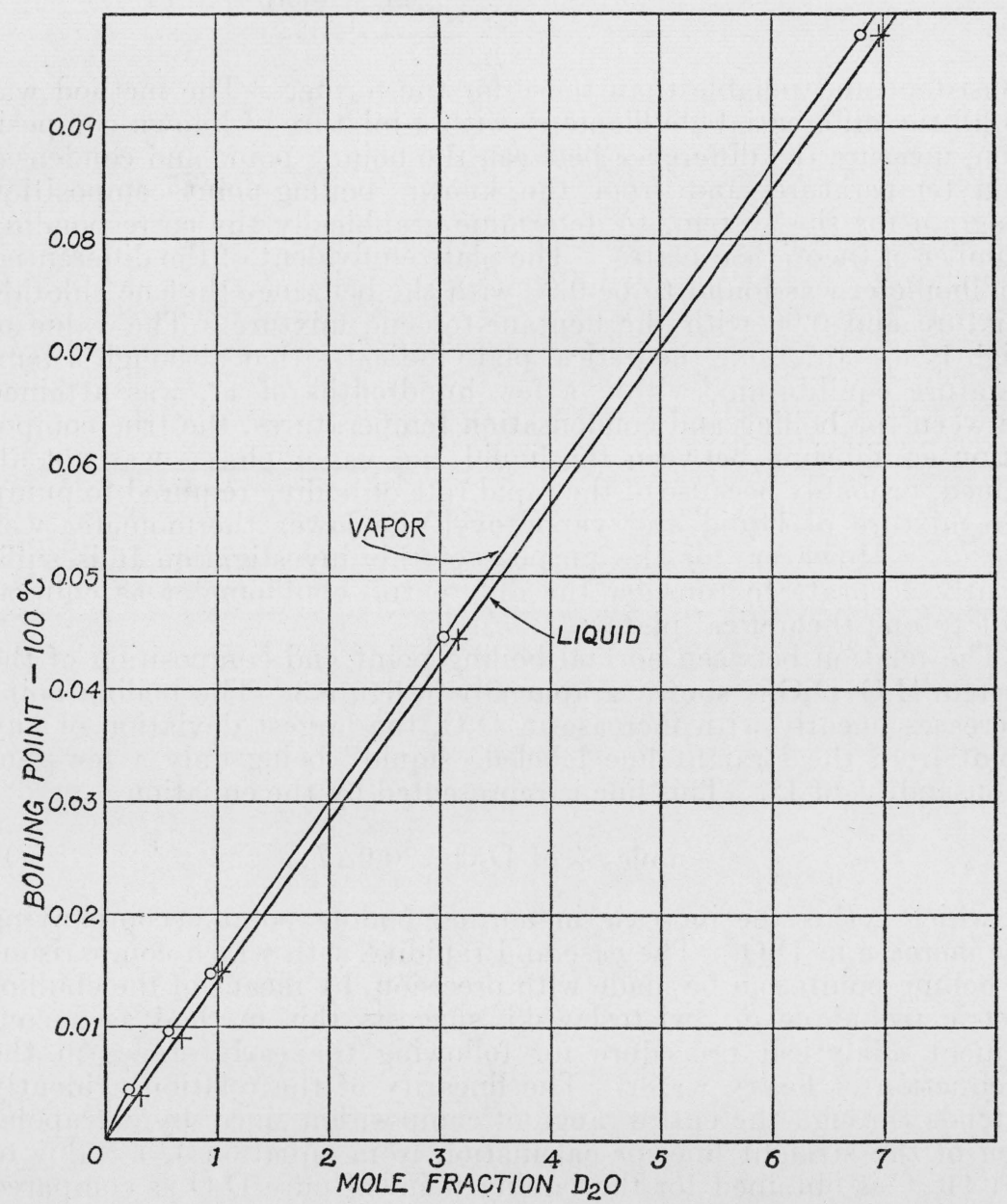

FIgURE 3.-Boiling-point-composition diagram.

either value gives practically the same result for the amount of HDO present. For example, in a mixture containing 1 percent of $\mathrm{D}_{2} \mathrm{O}$, the fraction of the $\mathrm{D}_{2} \mathrm{O}$ converted to $\mathrm{HDO}$ is 0.985 , if $K=3.26$ and 0.990 if $K=4$. For simplicity, without appreciably affecting the results, $K$ will be assumed to be 4. On the basis of this value of $K$ and the assumption that the vapor pressure of pure HDO is the geometric mean of the vapor pressures of $\mathrm{H}_{2} \mathrm{O}$ and $\mathrm{D}_{2} \mathrm{O}$, i. e., $p_{\mathrm{HDO}}=\left(p_{\mathrm{H}_{2} \mathrm{O}} p_{\mathbf{D}_{2} \mathrm{O}}\right)^{1 / 2}$, it has been shown by Wynne-Jones [20] that, for ideal solutions, the 
mole ratio of $\mathrm{D}$ to $\mathrm{H}$ in the liquid phase divided by the mole ratio of $\mathrm{D}$ to $\mathrm{H}$ in the vapor phase would be

$$
R=\left(p_{\mathrm{H}_{2} \mathrm{O}} / p_{\mathbf{D}_{2} \mathrm{O}}\right)^{1 / 2} .
$$

Values of $\left(p_{\mathrm{H}_{2} \mathrm{O}} / p_{\mathrm{D}_{2} \mathrm{O}}\right)^{1 / 2}$ corresponding to different temperatures can be computed by means of the equation

$$
\begin{aligned}
\log \frac{p_{\mathrm{D}_{2} \mathrm{O}}}{p_{\mathrm{H}_{2} \mathrm{O}}}= & -16.998671+\frac{268.8426}{T}+7.4971604 \log T \\
& -9.761107 \times 10^{-3} T+4.4288 \times 10^{-6} T^{2}
\end{aligned}
$$

obtained by Miles and Menzies [11] from comparative measurements of the vapor pressures of ordinary water and deuterium water in differential tensimeters. According to this equation $\left(p_{\mathrm{H}_{2} \mathrm{O}} / p_{\mathbf{D}_{2} \mathrm{O}}\right)^{1 / 2}=$ 1.0264 at $100.0^{\circ}$ and 1.0250 at $100.1^{\circ}$. The earlier data of Lewis and Macdonald [8] yield: $\left(p_{\mathrm{H}_{2} \mathrm{O}} / p_{\mathbf{D}_{2} \mathrm{O}}\right)^{1 / 2}=1.026$ between $100.0^{\circ}$ and $100.1^{\circ}$. Values of $R$ obtained graphically from figure 3 are given in table 3 . Although there appears to be a decreasing trend in the ratio with increase in $\mathrm{D}_{2} \mathrm{O}$, the precision of the graphical evaluation coupled with the small magnitude of the differences between boiling and condensation temperatures and the assumption that the differential ebulliometer is equivalent to exactly one theoretical plate does not justify recording $R$ to better than 1 percent. The uncertainty in the value of $R$ is relatively larger in the very dilute range. However, above $3 \%$ of $\mathrm{D}_{2} \mathrm{O}$ the agreement of $R$ with $\left(p_{\mathrm{H}_{2} \mathrm{O}} / p_{\mathrm{D}_{2} \mathrm{O}}\right)^{1 / 2}$ is adequate to show that mixtures of $\mathrm{D}_{2} \mathrm{O}$ and $\mathrm{H}_{2} \mathrm{O}$ are nearly perfect solutions at

\begin{tabular}{|c|c|c|c|c|}
\hline \multicolumn{2}{|c|}{ Liquid } & \multicolumn{2}{|c|}{ Vapor } & \multirow{2}{*}{$R$} \\
\hline $\begin{array}{l}\text { Mole frac- } \\
\text { tion }\end{array}$ & Mole ratio & $\begin{array}{l}\text { Mole frac- } \\
\text { tion }\end{array}$ & Mole ratio & \\
\hline $\begin{array}{l}0.01 \\
.02 \\
.03 \\
.04 \\
.05 \\
.06 \\
.07\end{array}$ & $\begin{array}{r}0.0101 \\
.0204 \\
.0309 \\
.0417 \\
.0526 \\
.0638 \\
.0753\end{array}$ & $\begin{array}{l}0.0088 \\
.0188 \\
.0287 \\
.0387 \\
.0485 \\
.0584 \\
.0684\end{array}$ & $\begin{array}{r}0.0089 \\
.0192 \\
.0296 \\
.0403 \\
.0510 \\
.0620 \\
.0734\end{array}$ & $\begin{array}{l}1.13 \\
1.06 \\
1.04 \\
1.03 \\
1.03 \\
1.03 \\
1.03\end{array}$ \\
\hline
\end{tabular}
the boiling point.

TABLE 3.-Ratio of $\mathrm{D}_{2} \mathrm{O} / \mathrm{H}_{2} \mathrm{O}$ in the liquid to $\mathrm{D}_{2} \mathrm{O} / \mathrm{H}_{2} \mathrm{O}$ in the vapor

\section{REFERENCES}

[1] E. C. Bromiley and D. Quiggle, Ind. Eng. Chem. 25, 1136 (1933).

[2] A. Eucken and K. Schäfer, Z. anorg. Chem. 225, 319 (1935).

[3] E. S. Gilfillan, Jr., J. Am. Chem. Soc. 56, 2201 (1934).

[4] N. F. Hall and T. O. Jones, J. Am. Chem. Soc. 56, 749 (1934).

[5] J. Horiuchi and G. Okamoto, Bul. Chem. Soc. Japan 10, 503 (1935).

[6] V. K. LaMer and W. N. Baker, J. Am. Chem. Soc. 56, 2641 (1934).

[7] G. N. Lewis and R. E. Cornish, J. Am. Chem. Soc. 55, 2616 (1933).

[8] G. N. Lewis and R. T. Macdonald, J. Am. Chem. Soc. 55,, 3057 (1933).

[9] D. B. Luten, Jr., Phys. Rev. 45, 161 (1934).

[10] C. H. Meyers, BS J. Research 9, 807 (1932) RP508.

[11] F. T. Miles and A. W. C. Menzies, J. Am. Chem. Soc. 58, 1067 (1936).

[12] E. Pahlavouni, Bul. soc. chim. Belg. 36, 543 (1927).

[13] M. A. Rosanofi and C. W. Easley, J. Am. Chem. Soc. 31, 980 (1909). 
[14] E. R. Smith and M. Wojciechowksi, Bul. int. acad. Polonaise A1936, 1; Roczniki Chem. 16, 104 (1936).

[15] W. Swiętosławski, Ebulliometry, p. 7, 11, 35. The Jagellonian Univ. Press, Krakow (1936).

[16] B. Topley and H. Eyring, J. Chem. Phys. 2, 217 (1934).

[17] L. Tronstad, J. Nordhagen, and J. Brun, Nature 136, 515 (1935).

[18] E. W. Washburn and E. R. Smith, J. Chem. Phys. 1, 426 (1933).

[19] E. W. Washburn and E. R. Smith, BS J. Research 12, 305 (1934) RP656.

[20] W. F. K. Wynne-Jones, J. Chem. Phys. 3, 197 (1935).

Washington, October 2, 1936. 